\title{
EL GÉNERO VALERIANELLA EN LA PENÍNSULA IBÉRICA. II
}

\author{
R. Fanlo Domínguez*
}

\section{RESUMEN}

Se revisan las especies de la sección Coronatae del género Valerianella Miller. Se incluye también una clave para las secciones.

Hace poco terminamos la primera nota para los Anales del Instituto Botánico A. J. Cavanilles, de Madrid (volumen en homenaje a S. Rivas Goday) y ahora publicamos la segunda, con otras observaciones originales derivadas del estudio detenido en el herbario JACA, completado con lo que vimos en los herbarios madrileños MA y MAF, del Jardín Botánico y Facultad de Farmacia respectivamente.

Seguimos el método morfológico, con estudio detenido de los frutos maduros, precisamente el utilizado por todos los autores para diferenciar tanto especies como secciones. Dadas las características de sus especies anuales efímeras, creo sinceramente que urge revisar ahora los frutos del material español y precisar los límites asignados a cada sección o especie. Posteriormente intentaremos relacionar dichos caracteres con los florales y vegetativos, así como los ecológicos, en un intento para lograr el conocimiento sistemático en género tan interesante para la flora española.

En el material estudiado ahora, se observa que es urgente precisar los límites entre algunas secciones de las admitidas en las floras consultadas.

Al final del presente trabajo intento exponer en forma de clave los caracteres más utilizados. En trabajos posteriores ensayaremos de perfeccionar dicha clave hasta delimitar, si es posible, cada sección con claridad y utilizando varios caracteres discriminantes. Dicha clave provisional ya permite al no iniciado comprender el sentido que damos a la interpretación de algunos caracteres morfológicos en frutos de Valerianella.

Resumiendo, entre los caracteres más utilizados como discriminantes al nivel de sección tenemos: 1) relación entre los dos sacos estériles y el

(*) Centro Pirenaico de Biología Experimental. Apartado 64. JACA (Huesca), España. 
fértil ; 2) la presencia de tejido esponjoso; 3) forma, tamaño y acrescencia del cáliz persistente en el fruto maduro; y 4) relación entre el tamaño de dicho cáliz y resto del fruto.

Revisamos en este trabajo la sección Coronatae Boiss.

\section{SECCIÓN CORONATAE BOISS}

Esta sección está representada en la península por tres especies: $V$. multidentata, $V$. coronata y $V$. discoidea.

Valerianella multidentata Loscos et Pardo.

Es un taxon descrito de la tierra baja aragonesa; se caracteriza por poseer más de seis divisiones en el cáliz; todas llegan cerca de la base y son de igual longitud. Interior del cáliz completamente glabro, con sacos estériles desarrollados y en conjunto iguales al fértil. Dicho fruto jamás rebasa los dos milímetros de longitud.

Los dibujos que adjuntamos pertenecen, uno al pliego repartido por LOSCOS y el otro a nuestro herbario. Al observar en otros herbarios pliegos de este taxon hemos comprobado que existe la posibilidad de confundirlo con variedades de $V$. discoidea que pueden presentar también gran número de divisiones en el cáliz; por tanto creemos que $V$. multidentata se distingue fundamentalmente de sus afines $(V$. coronata y $V$. discoidea) por sus frutos menores, por la igualdad de los muchos lóbulos del cáliz, divididos hasta su base (es decir, sin dientes laterales) y por la ausencia de pilosidad en el interior calicinal.

Apenas se ha publicado nada sobre esta especie desde su descripción; coloniza lugares secos y caldeados de zonas más o menos nitrófilas. Nosotros la poseemos de la provincia de Huesca (Vedat de Fraga) y la vimos en MA de Castelserás (119260) y en MAF de Castelserás (54807).

Comparamos en el dibujo los frutos de un ejemplar nuestro con uno del pliego de Loscos y Pardo en MAF (54807).

Por la bibliografía conocemos otra localidad de esta especie: Puymoreno (entre Alcañiz y Samper).

Creemos, igual que Loscos y PARDo, que no se debe subordinar como subespecie a $V$. coronata; idea que sugiere WILLKomm, ya que el estudio detenido del fruto abona el criterio de mantenerla como especie.

Valerianella coronata (L.) DC.

(= Valerianella locusta L. var. coronata L.).

Se caracteriza esta especie por fruto con cáliz desarrollado, formando seis o más lóbulos. El interior del fruto es lampiño y su tamaño variable 
entre 3 y $4 \mathrm{~mm}$ de longitud por 1,5 a $2 \mathrm{~mm}$ de anchura. Algunos ejemplares aparecen con más de las seis divisiones calicinales típicas (hasta doce y catorce) y por su posición deben interpretarse como laterales de sus lóbulos principales. Todos los ejemplares de $V$. coronata observados presentan sacos estériles desarrollados.

Viendo las descripciones que de este taxon hacen algunas floras, comprobamos que coinciden al atribuirle unos sacos estériles desarrollados, pero discrepan unas de otras en su tamaño relativo al compararlos con la parte fértil.

Creemos que para las $V$. coronata ibéricas conviene utilizar el carácter de sacos desarrollados. El tamaño aproximado de los sacos estériles y su relación con el fértil se aprecia claramente en los cortes transversales del fruto, aunque hemos encontrado ejemplares con gran variabilidad en el tamaño de los sacos aun dentro del mismo pie. Adjuntamos el dibujo de un ejemplar, en el que se aprecian los sacos filiformes de unos frutos, mientras que en otros posee sacos desarrollados. La diferencia en los frutos quizá se base en la madurez de los mismos, aunque el carácter de ser más anchos en la base es común a los frutos de la sección Siphonocoele.

Podría tratarse de una especie que haga la transición entre las Coronatae y Siphonocoele.

Se incluyen dos icones, uno perteneciente a un ejemplar típico y el otro a uno con más de seis divisiones; dichos ejemplares se encuentran depositados en nuestro herbario JACA.

Comparando detenidamente esta especie con ejemplares de $V$. multidentata es difícil la confusión, ya que las divisiones del cáliz son irregulares sin alcanzar su base y nunca tan semejantes entre sí como en $V$. multidentata; además el tamaño del fruto es siempre bastante mayor en V. coronata.

Es una planta nitrófila presente en comunidades de Secaletea y Chenopodietea.

Valerianella discoidea (L.) Lois.

(= Valerianella locusta L. var. discoidea L.).

Especie próxima a la anterior. Presenta sacos estériles más desarrollados que el fértil y un cáliz interiormente piloso; con seis o más divisiones, en algunas ocasiones irregulares y que no llegan hasta la base.

El carácter principal utilizado en la bibliografía consultada para diferenciarla de $V$. coronata, es la presencia de villosidad en la parte interna del cáliz. En algunas ocasiones podría confundirse con $V$. multidentata, atendiendo únicamente al número de divisiones calicinales y no al carácter típico del interior del cáliz.

Muy difundida en nuestra península, se encuentra ligada a unos ambientes ruderalizados. 


\section{CLAVE DE SECCIONES PARA EL GÉNERO VALERIANELLA MILLER}

1. Frutos de dos formas y terminados en tres prolongaciones muy marcadas: Cornigerae.

1. Frutos todos semejantes.

2. Sacos estériles mayores o iguales al fértil, no filiformes.

3. Con tejido esponjoso en los frutos: Locustae.

3. Sin tejido esponjoso.

4. Cáliz apenas desarrollado: Platycoele.

4. Cáliz muy desarrollado: Coronatae.

2. Sacos estériles menores en conjunto que el fértil, filiformes: Siphonocoele.

Entre las especies españolas pertenecientes a la sección Siphonocoele que ahora estudiamos, destaca claramente una que por sí sola podría formar una sección aparte; se trata de $V$. fusiformis, especie endémica española que se caracteriza por poseer un fruto pediculado, con forma y tamaño que la separan netamente del resto de las especies con sacos estériles tubiformes.

\section{BIBLIOGRAFIA}

DAvis, P. H.. - 1972. Flora of Turkey. Volume four. Edinburgh. FIORI, A. - 1969. Nuova flora analitica d'Italia. Volume secondo. Bologna. Loscos, F. y PARDo, J. - 1866. Serie imperfecta de las plantas aragonesas. Alcañiz. RouY, G. - 1903. Flore de France. Tome VIII. La Rochelle.

Willkomm, M. y LANGe, J. - 1861. Prodromus florae Hispanicae. Stuttgart.

\section{LEYENDAS DE LAS FIGURAS}

\section{Figura 1.}

A. V. multidentata, Vedat de Fraga, 18 mayo 1972. 1, vista anterior; 2, sección transversal.

B. V. multidentata. Castelserás, 8 mayo 1875. Pliego de Loscos y Pardo. 1, vista anterior; 2, sección transversal (MAF 54807).

C. V. coronata. Guadalix de la Sierra, 23 mayo 1968. 1, vista anterior; 2, sección transversal. Ejemplar de más de seis divisiones en el cáliz.

D. V. coronata. Villabuena, 6 julio 1958. 1, vista anterior; 2, sección transversal. Ejemplar normal.

Figura 2.

A. V. discoidea. Laguna de la Playa, Bujaraloz, 18 mayo 1972. 1, vista anterior; 2, sección transversal. Ejemplar típico.

B. $\quad V$. discoidea. Albeda (Huesca), 15 mayo 1971. 1, vista anterior; 2, sección. Ejemplar de más de seis divisiones.

C. V. coronata. El Cotillo, Mora de Toledo, abril 1967. 1, vista lateral; 2 y 3 , secciones transversales con diferentes tamaños en los sacos estériles. 


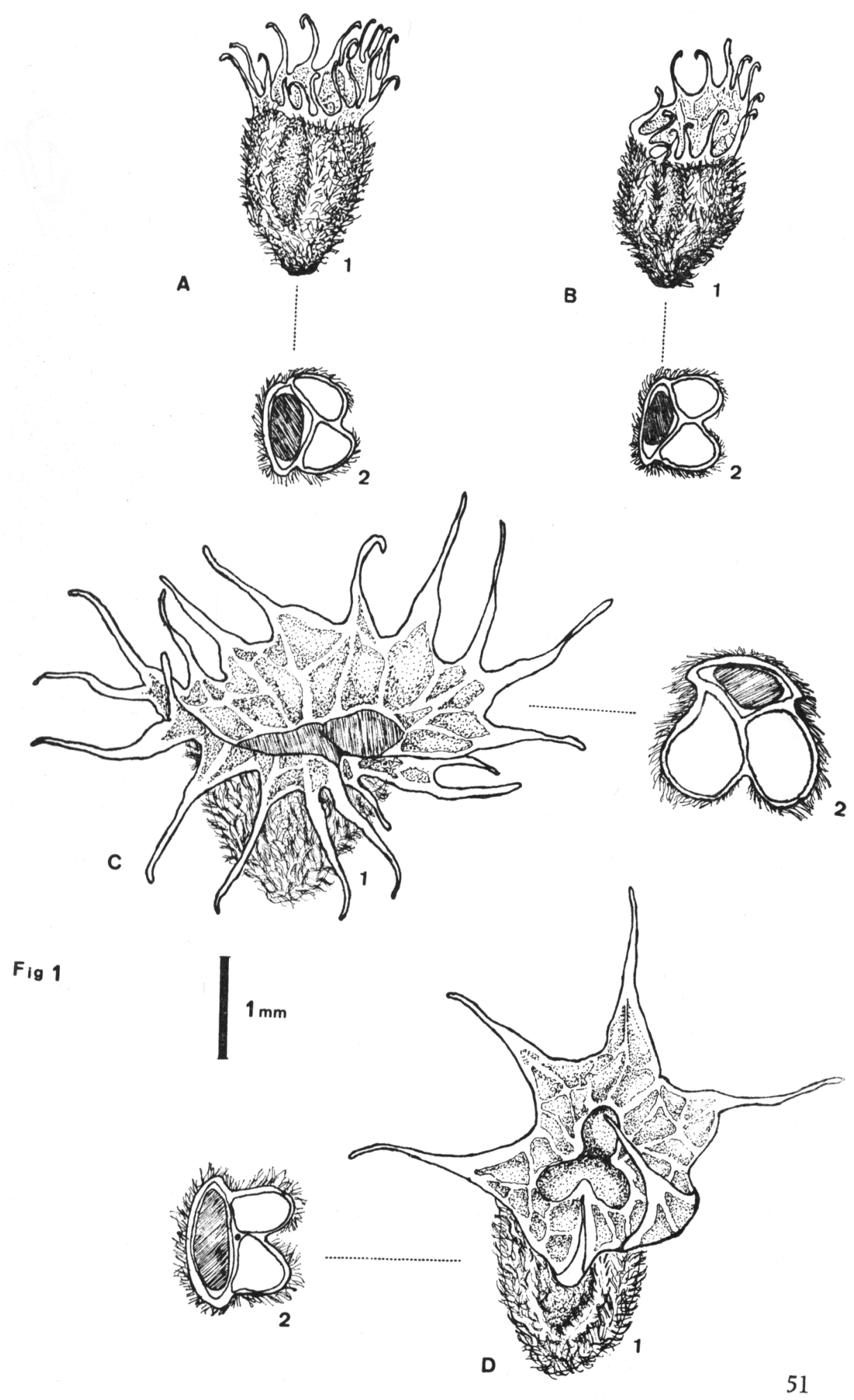




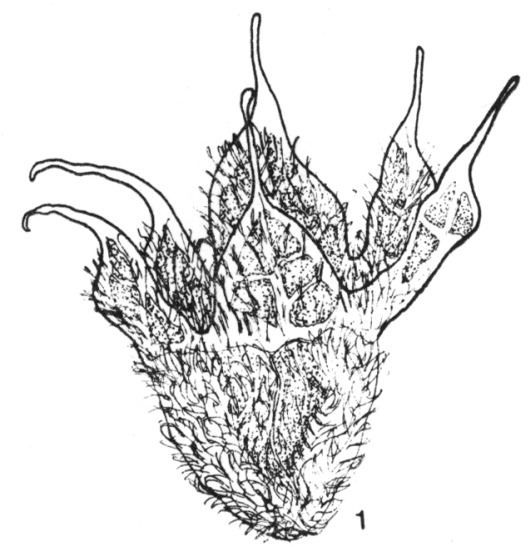

A
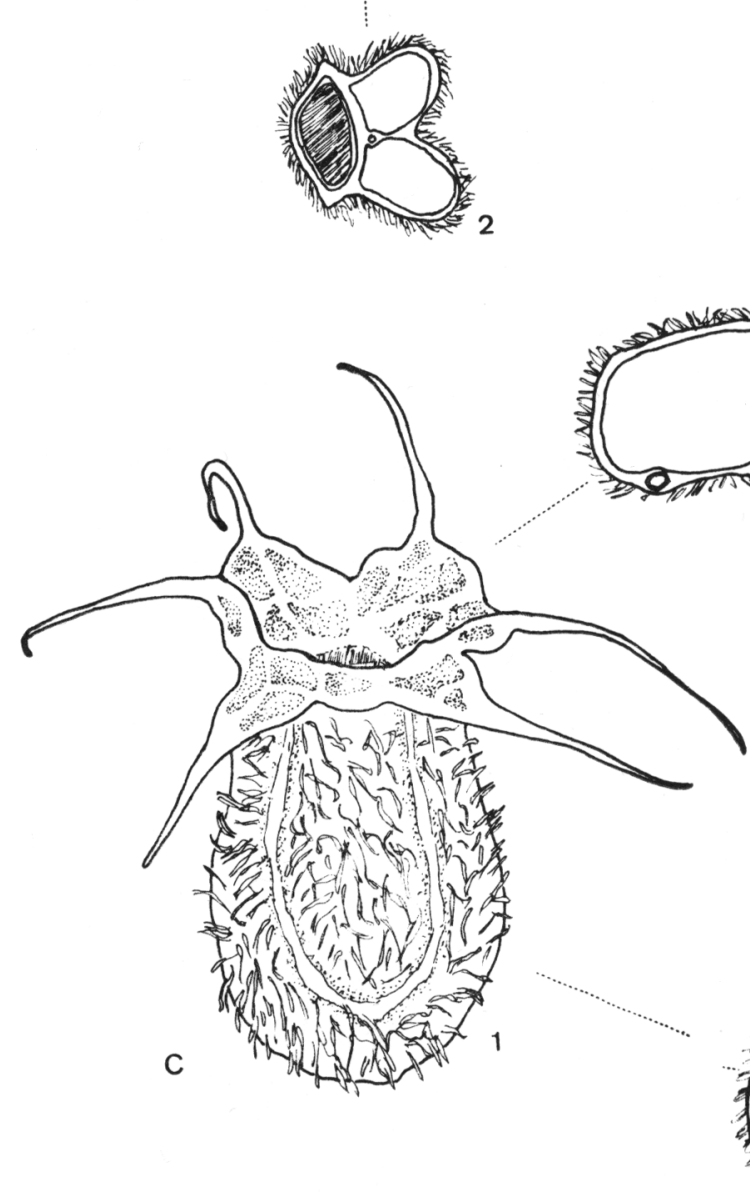
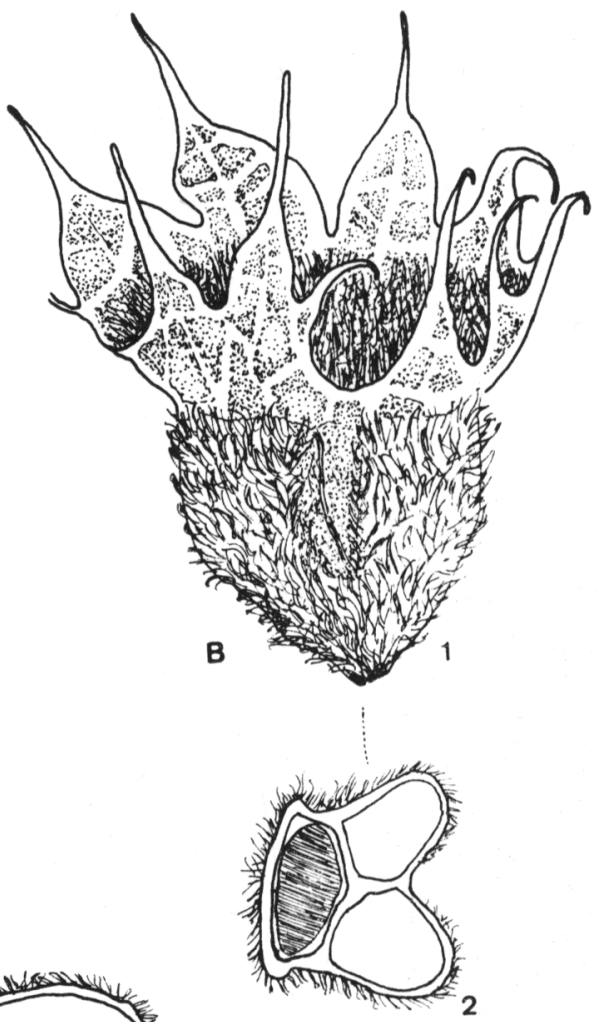

Fig 2

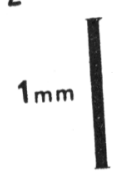

